\title{
Full-text publication of abstracts presented at meetings of a Latin American scientific society
}

\author{
Manuela Dicembrino, M.D. ${ }^{a}$, Mariana Anderson, M.D. ${ }^{a}$, Ana Gabriela Vely, M.D. ${ }^{a}$, \\ María Fabiana Ossorio, M.D. ${ }^{a}$ and Fernando Ferrero, M.D. ${ }^{a}$
}

\begin{abstract}
Objective. To estimate the proportion of abstracts presented at meetings of the Latin American Society for Pediatric Research that are fully-published, to describe the reasons for not publishing papers, and to assess the impact of funding on the publication rate.

Methods. Abstracts presented at meetings held between 2005 and 2009 were included. Authors were contacted and invited to take a survey on the publication of their work or the reasons not to do it.

Results. Information was collected on $232(71.4 \%)$ of the 325 abstracts presented. Of these, $58.6 \%$ were fully-published $(136 / 232)$. Funded studies $(40.0 \%)$ had more chances of publication (OR: 2.2; 95\% CI: 1.2-3.9). "Lack of time" was the most common reason for failure to publish (35/96).

Conclusion. $58.6 \%$ of abstracts presented at meetings of the Latin American Society for Pediatric Research, were published as full-text articles; lack of time was the most common reason for failure to publish. Funded research had more chances of being published.

Key words. medical bibliography, periodic publications, research report.
\end{abstract}

http:/ /dx.doi.org/10.5546/aap.2014.eng.532

\section{INTRODUCTION}

Research process can be considered finished only when its results are subject to the scientific community's scrutiny. Both the relevance of publication in relation to the dissemination of knowledge and the moral obligation of publishing any and all research results that could benefit societies are beyond dispute. Moreover, not publishing results of valid investigations may contribute to sustaining or even worsening "publication bias."

a. Department of Teaching and Research, Hospital General de Niños Pedro de Elizalde, Buenos Aires.

E-mail Address:

Fernando Ferrero, M.D.: fferrero@intramed.net

Conflict of Interest: None.

Received: 6-3-2014

Accepted: 7-21-2014
Scientific societies are the ideal setting for the initial presentation of research. However, not many of the abstracts presented at conferences are actually subsequently published. ${ }^{2}$

In general, not more than $50 \%$ of abstracts presented at medical meetings are published as a full-text article. ${ }^{3}$

In Latin America, the Latin American Society for Pediatric Research (Sociedad Latinoamericana de Investigación Pediátrica, SLAIP) has encouraged local scientific production for the past 50 years, but there are no data on the proportion of abstracts presented at its meetings that are subsequently fully-published.

The objective of this article is to estimate the proportion of abstracts presented at the SLAIP's annual meetings that were subsequently published in scientific journals; to describe the most common reasons for not publishing them; and to assess how funding impacts the publication rate.

\section{MATERIAL AND METHODS}

This was an observational study that included all articles presented at the SLAIP's annual meetings held between 2005 and 2009. One of the authors of each study was identified and contacted (by e-mail, telephone or in person) and invited to complete a brief survey (initially, the first listed author was contacted; if contact was unsuccessful, the author listed in the last place was contacted; and then any other author). Surveys were closed and self-administered (see Annex). One survey was sent for each abstract, even if one person was the author of more than one article.

A valid publication was defined as a publication in a renowned periodic scientific journal with an international standard serial number (ISSN). The accuracy of data collected on publications was verified and contrasted with the Medline and Lilacs databases or, if not possible, with each specific publication.

Analysis: Survey data were adequately registered and identifiable data were left out. Categorical outcome measures were expressed as percentages with $95 \%$ confidence intervals 
(CI). The association between proportions was assessed using a chi squared test. A value of $p$ $<0.05$ was considered significant.

Ethical considerations: The survey included information regarding consent. Data analysis left out any personal data. Authorization was obtained from the institutional committees of Hospital General de Niños Pedro de Elizalde, institution where researchers work. The study was registered at the Research Public Registry of the Ministry of Health of the City of Buenos Aires under number 32/13.

\section{RESULTS}

In the study period (2005- 2009), 325 abstracts were presented, the authors of $263(80.9 \%)$ were contacted, and information was obtained on 232 $(71.4 \%)$ (Table 1).

Abstracts were from 11 countries (Table 2).

Only $58.6 \%$ (95\% CI: $52-65)$ of abstracts were fully-published $(136 / 232)$. In all cases, bibliographic references were checked for veracity. Of those finally published, 90 were included in journals indexed in Medline; 74, in Lilacs; and 48, in both databases (Table 2).

TABLE 1. Abstracts presented at five meetings of the Latin American Society for Pediatric Research

\begin{tabular}{lcccc}
\hline Year & Meeting & Country & City & Abstracts \\
\hline 2005 & XLIII & Brazil & Ribeirao Preto & 86 \\
2006 & XLIV & Argentina & Bariloche & 57 \\
2007 & XLV & Chile & La Serena & 56 \\
2008 & XLVI & Peru & Urubamba & 60 \\
2009 & XLVII & Paraguay & Asuncion & 66 \\
\hline Total & & & & 325 \\
\hline
\end{tabular}

Of the 232 analyzed abstracts, 92 (39.6\%) indicated to have received funds, 78 were statefunded while 14 were privately-funded. The highest number of funded studies was found in Chile $(59.0 \%)$ (Table 3).

Studies with some sort of funding had more chances of being published than those that received no funds $(69.5 \%$ versus $51.4 \%, p=0.006$; OR: $2.1 ; 95 \%$ CI: 1.2-3.7).

Of the 96 abstracts that were not published, information on the reason was obtained for 66; lack of time was the most common reason $(\mathrm{n}=$ 35) (Table 4).

\section{DISCUSSION}

Our study shows that nearly $60 \%$ of abstracts presented at the SLAIP's meetings were subsequently fully-published in scientific journals.

Although the proportion of abstracts presented at scientific meetings that are published is highly variable, a review on this subject that combined data from 79 reports (29 729 abstracts) estimated an average publication rate of $44.5 \%{ }^{3}$

Such rate may be higher in meetings held in the Northern Hemisphere, particularly in relation to certain specialties.

In pediatrics, publication rates range between $45 \%$ and $60 \% .{ }^{4,5}$ Although there is little information on this subject in Latin America, publication rates appear to be noticeably lower: $25.5 \%$ in Chile (gastroenterology), ${ }^{6} 11.3 \%$ in Argentina (pediatrics), ${ }^{7}$ and $26.6 \%$ in Brazil (orthopedics). ${ }^{8}$

Such difference with other meetings in this region is probably related to the characteristics of the SLAIP and its attendees. On one hand, no case reports, case series or reports on professional experience are accepted by the SLAIP. On the

TABLE 2. Abstracts presented at five meetings of the Latin American Society for Pediatric Research and those fully-published, by country and index

\begin{tabular}{lcccccccccccc}
\hline Country & Presented & $\%$ & Analyzed & $\%$ & Published & $\%$ & Medline & $\%$ & Lilacs & $\%$ & Both & $\%$ \\
\hline Argentina & 92 & 28.3 & 88 & 37.9 & 56 & 63.3 & 38 & 66.7 & 36 & 63.2 & 25 & 52.1 \\
Bolivia & 4 & 1.2 & 2 & 0.8 & 1 & 50.0 & 1 & 100.0 & 0 & 0.0 & 0 & 0.0 \\
Brasil & 74 & 22.8 & 36 & 15.5 & 24 & 66.7 & 19 & 79.2 & 18 & 75.0 & 14 & 17.6 \\
Chile & 79 & 24.3 & 56 & 24.1 & 37 & 66.1 & 30 & 81.1 & 13 & 35.1 & 8 & 16.7 \\
México & 10 & 3.1 & 8 & 3.4 & 4 & 50.0 & 0 & 0.0 & 0 & 0.0 & 0 & 0.0 \\
Perú & 43 & 13.2 & 32 & 13.8 & 9 & 28.1 & 3 & 33.3 & 6 & 66.7 & 1 & 2.1 \\
Paraguay & 14 & 4.3 & 8 & 3.4 & 3 & 37.5 & 0 & 0.0 & 1 & 33.3 & 0 & 0.0 \\
Otros & 9 & 2.7 & 2 & 0.9 & 2 & 100 & 0 & 0.0 & 0 & 0.0 & 0 & 0.0 \\
\hline & 325 & & 232 & & 136 & 58.6 & 90 & 66.1 & 74 & 54.4 & 48 & 35.2 \\
\hline
\end{tabular}


other hand, in general, meeting attendees are clearly devoted to research. It is known that the ultimate goal for professionals who work on research is to have their studies published.

Only $40 \%$ of researchers indicated to have received some sort of funding. In spite of the slight differences by country, this value reflects a regional reality: there is limited financial support for investigations. Spending on innovation and development (2000-2005) in this region's countries ranges from $0.1 \%$ (Peru) to $0.6 \%$ (Chile) of the GDP, ${ }^{9}$ compared to $1.13 \%$ in Spain. ${ }^{10}$ It should be noted that most of the investments are made by the government, ranging from $72 \%$ in Argentina to $53 \%$ in Brazil, versus the $31 \%$ provided by the United States government. ${ }^{11}$

Notwithstanding the preceding, it is clear that having received funds increases the chances of having research results fully-published. ${ }^{12}$

Although our study included only those abstracts presented at five of the SLAIP's meetings, we were able to have enough abstracts to reasonable estimate an accurate publication rate. In addition, the period selected for our study allowed surveyed authors to easily recall abstracts involved and a sensible time for reaching publication considering that the average time is usually not less than two years. ${ }^{13}$

Even though data of abstracts whose authors did not participate in our study were not analyzed, the high response rate makes a significant bias unlikely. Abstract quality was not analyzed either; we only considered publication in journals indexed in Pubmed and Lilacs as an indirect indicator of said quality.

TABLE 3. Funding of research whose abstracts were presented at meetings of the Latin American Society for Pediatric Research (2005-2009), by country and source of funding

\begin{tabular}{lccccc}
\hline & Total & Funded & $\%$ & Public & Private \\
\hline Argentina & 88 & 35 & 39.3 & 28 & 7 \\
Bolivia & 2 & 1 & 50.0 & 0 & 1 \\
Brasil & 36 & 13 & 36.2 & 12 & 1 \\
Chile & 56 & 33 & 59.0 & 31 & 2 \\
México & 8 & 1 & 12.5 & 0 & 1 \\
Paraguay & 8 & 2 & 25.0 & 1 & 1 \\
Perú & 32 & 7 & 21.9 & 6 & 1 \\
Venezuela & 2 & 0 & 0.0 & 0 & 0 \\
\hline Total & 232 & 92 & 39.6 & 78 & 14 \\
\hline
\end{tabular}

Other studies on this topic were also based on Pubmed searches for abstracts presented at scientific meetings, so it was possible to underestimate their publication rate for considering only one source of data. We decided to contact authors and then check the different databases for information accuracy.

In spite of the evidence indicating that biomedical research has significantly improved over the past 15 years, ${ }^{9}$ our study does not allow for a regional extrapolation because it is limited to a particular specialty, with a majority participation in the SLAIP by Argentina, Brazil and Chile.

In our study, lack of time was indicated as the main reason for failure to publish (53\%). Even in a sensitive subject matter as that of large, controlled clinical trials in oncology, lack of time was referred as the main reason for not publishing the study. ${ }^{14}$ This underscores

the importance of considering this aspect during research planning, including a schedule for writing the manuscript and for publishing management. Not publishing results is a continuous concern in the academic field, where strategies have even been developed to attempt to increase the publication rate, but there is no substitute for personal drive and commitment. ${ }^{15}$

To um up, $58.6 \%$ of abstracts presented at meetings of the Latin American Society for Pediatric Research were fully-published. Studies that had received some sort of funding had more chances of being published. Lack of time was the most commonly referred reason for not publishing them

Table 4. Reasons for not publishing abstracts presented at scientific meetings as full-text articles

\begin{tabular}{lc}
\hline Reason & $\mathbf{n}$ \\
\hline Lack of time & 35 \\
Insufficient sample size & 5 \\
Disagreement among authors & 4 \\
Pessimism regarding publication & 3 \\
Rejection & 3 \\
Results considered not significant & 2 \\
Lack of interest & 1 \\
Other articles showing similar results & 1 \\
Others & 12 \\
\hline Total & 66 \\
\hline
\end{tabular}




\section{Acknowledgments}

To Carlos Castillo Durán, M.D., for making a critical review of the manuscript and for his continuous devotion to the advancement of pediatric research.

\section{REFERENCES}

1. Wager E, Williams P. Project Overcome failure to Publish Negative Findings Consortium. "Hardly worth the effort"? Medical journals' policies and their editors' and publishers' views on trial registration and publication bias: quantitative and qualitative study. BMJ 2013;347:f5248.

2. Von Elm E, Costanza MC, Walder B, Tramèr MR. More insight into the fate of biomedical meeting abstracts: a systematic review. BMC Med Res Methodol 2003;3:12.

3. Scherer RW, Langenberg P, Von Elm E. Full publication of results initially presented in abstracts. Cochrane Database Syst Rev 2007;(2):MR000005.

4. Carroll AE, Sox CM, Tarini BA, Ringold S, et al. Does presentation format at the Pediatric Academic Societies' annual meeting predict subsequent publication? Pediatrics 2003;112(6 Pt 1):1238-41.

5. Riordan FA. Do presenters to paediatric meetings get their work published? Arch Dis Child 2000;83(6):524-6.

6. Weitz JC, Silva H. Presentación versus publicación: análisis de trabajos presentados en Congresos Chilenos de Gastroenterología 1998 al 2002. Gastroenterol Latinoam 2005;16(3):287-92.

7. Canosa D, Ferrero F, Melamud A, Otero P, et al. Publicación completa de trabajos presentados en el $33^{\circ}$ Congreso Argentino de Pediatria y análisis de factores que impidieron su publicación. Arch Argent Pediatr 2011;109(1):56-9.
8. Ejnisman L, Gomes GS, de Oliveira RG, Malavolta EA, et al. Publication rates of papers presented at the Brazilian Orthopedic Meeting. Acta Ortop Bras 2013;21(5):285-7.

9. Alger J, Becerra-Posada F, Kennedy A, Martinelli E, et al. Sistemas nacionales de investigación para la salud en América Latina: una revisión de 14 países. Rev Panam Salud Publica 2009;26(5):447-57.

10. Rodríguez Pomeda J. Indicadores iberoamericanos de I+D. Revista de Investigación en Gestión de la Innovación y Tecnología 2007;45. Available at : http:/ / www.madrimasd. org/revista/revista45/ImasDCifras/imasdcifras.asp. Accessed on: February 6, 2014].

11. Red de Indicadores de Ciencia y Tecnología Iberoamericana e Interamericana. Gasto en I+D por sector de financiamiento. Buenos Aires: RICYT;2014. Available at: http:/ / db.ricyt. org/query/AR,BO,BR,CA,CL,CO,CR,CU,EC,ES, GT,MX, PA,PT,PY,SV,US,UY,AL,IB/1990\%2C2011/GASIDSFPER. [Accessed on: February 6, 2014].

12. Domínguez P, Chiolo MJ, Davenport MC, Di Lalla S, et al. Evaluación de la producción científica del Hospital General de Niños Pedro de Elizalde, 2000-2011. Arch Argent Pediatr 2014;112(2):147-52.

13. Gregory TN, Liu T, Machuk A, Arneja JS. What is the ultimate fate of presented abstracts? The conversion rates of presentations to publications over a five-year period from three North American plastic surgery meetings. Can J Plast Surg 2012;20(1):33-6.

14. Krzyzanowska MK, Pintilie M, Tannock IF. Factors associated with failure to publish large randomized trials presented at an oncology meeting. JAMA 2003;290(4):495-501.

15. McGrail M, Rickard C, Jones R. Publish or perish: a systematic review of interventions to increaseacademic publication rates. Higher Education Research \& Development 2006;25:19-35. 
ANExx. Survey used to assess the publication of abstracts presented at the meetings of the Latin American Society for Pediatric Research

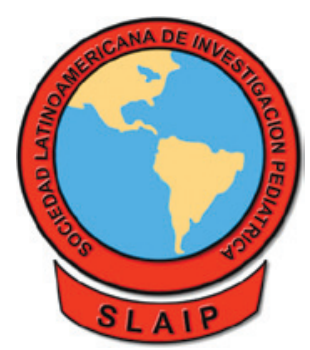

Survey

Assessment of scientific publication of abstracts presented at the SLAIP

\section{Dear Colleague,}

You are hereby invited to participate in a study on the publication of scientific abstracts presented at the meetings of the Latin American Society for Pediatric Research. As you might know, although desirable, the number of scientific papers presented at conferences that are subsequently actually published in full is limited. To estimate our scientific output and eventually identify factors that may hinder publication will help us design strategies to overcome such hurdles. You are being contacted because you presented an abstract at one of the SLAIP's meetings. Your participation in this survey is voluntary. Your personal data will be conveniently left out from the information required for the study so that your identity is kept confidential. By completing this survey you are giving your consent to participate in the study.

Thank you!

\section{Abstract title:}

Year of presentation at the SLAIP:

Please, mark with an " $X$ " the corresponding answer.

1) Was your project funded?

Public funds:

Private funds:

No:

2) Was your project published in a scientific journal? Yes (including press):

No:

If "Yes," provide the authors' names, the study title, the journal, volume, page, year (as if quoting a bibliographic)

If "No," what do you think is the most important reason why your research was not published? (select only one answer).

$\square$ Lack of interest

$\square$ Lack of time

$\square$ Disagreement among authors

$\square$ Other studies with similar or contradictory results

$\square$ You considered that results were not significant

$\square$ Insufficient sample size

$\square$ Problems with the statistical analysis

$\square$ Pessimism among authors regarding acceptance for publication

$\square$ Problems with funding

$\square$ Not accepted for publication

$\square$ Other reasons 